Paediatrica Indonesiana $14: 109$ - 112. July - August 1974. 109

From the Cardiac Center, Dr. T jüto Mangunkusumo General Hospital, Jakarta

\title{
Present Cardiologic Problems in Indonesia
}

\section{by}

\section{I.S.F. RANTI}

\section{H:storical notes}

Before World War II, the field of Cardiology was covered mainly by Internal Medicine. Cardiology practized at that time mainly consisted of prescribing digitalis and other cardiac glycosides. Chinine and its derivatives primarily given to combat malaria or as antipyretics, heralded its use as an antiarrhythmic drug. Aspirin and other salicylates although intended as an antipyreticum could well be considered as the first step in routine treatment of Rheumatic Fever. Nowadays, seemingly salicylates can be used as an anticoagulant agent.

Herb extracts and decoctum prepared from folia orthosiphonis and other allied herb-mixtures were already known for their diuretic properties. Even for "tranquilizing" a "cardiac" patient the "dukun" (indigenous medical man) seemed to have an answer (Datura Stramonium and Cannabis Indica leaves).

Received 1st. Feb. 1974.
Containing alkaloids with parasympatholytic properties one can easily imagine their action on bradyarrhythmic complications of let say a Myocardial Infarction. Javanese women, eventhough without "trim-glim" exercise-programs are well known for their slender and gracious appearance. To Western eyes it could be their secret is "Djamu-Singset" (A slim. trim herb mixture).

An Indonesian styled physical fitness program called "Orhiba" seems recently to become more popular, at least the method is less expensive.

With the introduction of Cardiac Catheterization techniques (1958) in Indonesia, Cardiology was no more the privilage of Adult Internal Medicine.

Pediatricians faced with the problems of Congenital Heart Diseases made their stage appearance giving a much needed impetus to Cardiology. As new techniques imply more technical and theoretical problems, soon other branches of the medical and parame- 
dical field as Physiology, Rontgenology and Medical Electronics become involved.

The steady increase of the number of Cardiovascular diseases and the progresses made in the diagnostic and surgical procedures intensified the activities in the field of Cardiology. At the present time these activities have grown beyond medical and technicall aspects, creating a variety of socio-economic problems, requiring active private and governmental participation and cooperation.

The Indonesian Heart Association was established in 1960 and later affiliated with the Asian Pacific Society of Cardiology and the International Society of Cardiology. At present the Association comprises a body of 25 numbers.

As a realization of private participation the Indonesian Heart Foundation was founded in 1964. In 1966 the National Heart Institute was established with the purpose of combining all available sources (manpower and material).

\section{Cardiological Activities}

A few general information about our couniry might be helpful for a better understanding of the problems faced by Indonesian Cardiologists. Actually, we have a population of roughly 120 millions living on scattered islands which are more or less densely populated with Indonesians (although from different ethnic ori- gin) and minority groups as Chinese, Indians, Eurasians, etc. Although living side by side peacefully, these groups tend to maintain their own living and dietary habits, cultural patterns and religions. The actual age structure is of relatively young type, and the process of urbanization just started recently. In overpopulated towns as Jakarta, becoming industriallised, the changing living and dietary habits, stress and other environmental factors are already influen. cing the morbidity pattern.

Figures from our Out-Patient-Departmenit collected in the last five years show a steady increase in Coronary Artery Disease and Hypertensive cases, and a decline in Rheumatic Heart Disease cases.

The major problems of heart disease in this country are in the field of:
a) Congenital Heart Diseases
b) Rheumatic Heart Diseases
c) Diphtheric Myocarditis
d) Coronary Artery Diseases
e) Cardiomyopathies
f) Cardiac Surgery
g) Epidemiology

\section{Congenital Heart Diseases}

Before 1958 the accent was on clinical cardiology, cardiac evaluation was based mainly on clinical findings (physical diagnosis, electrocardiography and X-Ray).

The need for accurate haemodynamic evaluation was felt, so in $\mathbf{1 9 5 8}$ 


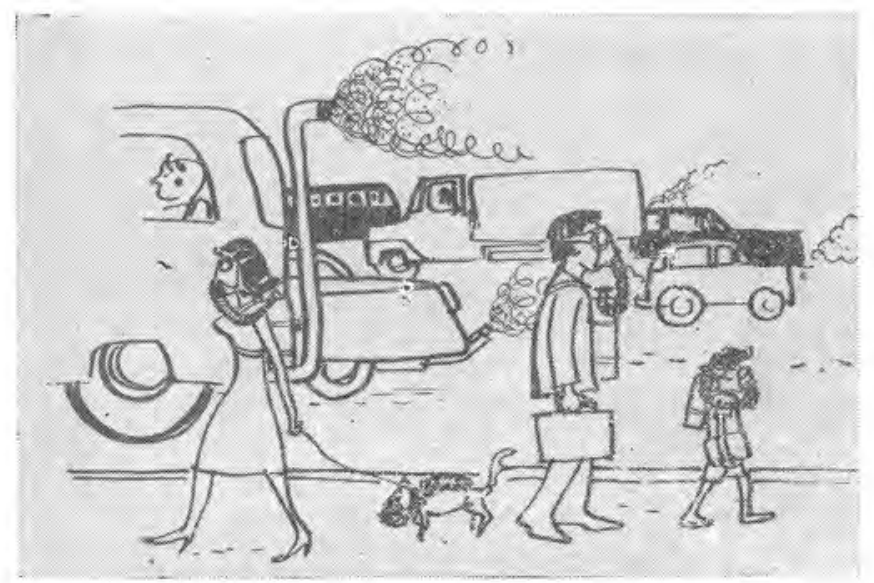

air pollution

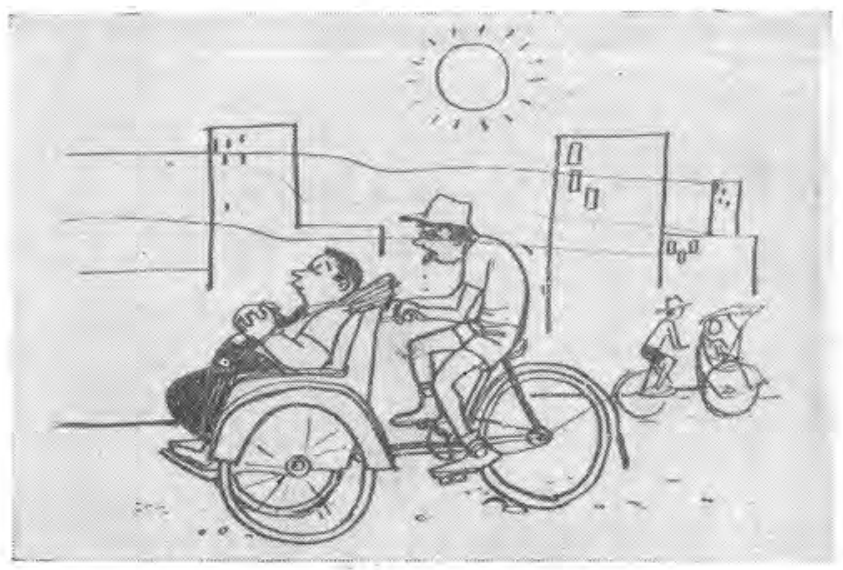

Explotation de L'homme par L'homme Solution for Air Pollution? 

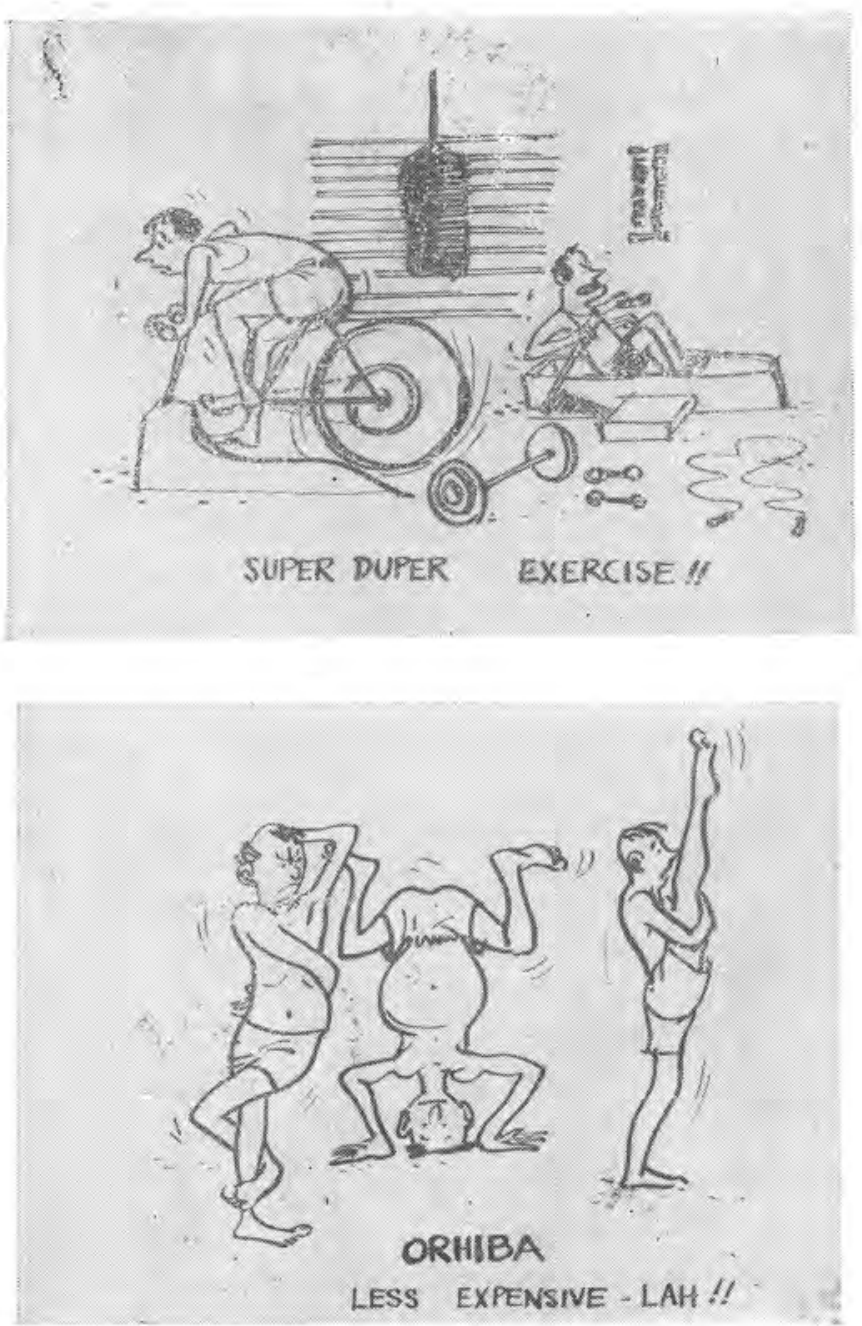
cardiac catheterization was started, but progress was slow due to lack of adequate equipment. Gradually when this was improved, Right and Left Heart Catheterization became routine, paving the way for surgeons. Non-invansive examination techniques such as Phono cardiography and Apexcardiography were developed. Besides conventional electrocardiography, vectorcardiography is used for correlation studies.

\section{Rheumatic Heart Diseases}

Rheumatic Heart Disease is rampant, affecting children and adolescents with crippling valvular deformities and rigid prophylactic regimens in a rheumatic subject are probably responsible for the decline of rheumatic cases in our Out Patient Department.

\section{Diphtheria Myocarditis.}

Although primarily a problem for Pediatricians, the high incidence of myocarditis (15-20\% of total Diphtheria cases) in our country calls for cardiologic support, the dreaded occurrence of a total block calls for modern cardiologic techniques as cardiac pacing.

\section{Coronary Artery Diseases}

In Jakarta the scourge of this disease, allready reaching epidemic proportions in industrial countries, is notilicable. Premature deaths in men's most productive years represent a true disaster for the families and country.
For screening purposes, beside accurate history taking, conventional Electrocardiography and Vectorcardiography and Laboratory methods; the exercise test (Master's and Ergometrics) become a routine procedure.

In 1971 an Intensive Coronary Care Unit in the Dr. Tjipto Mangunkusumo General Hospital, Jakarta was established for the acutely inl, needing Coronary Care. Temporary pacing has just started.

Anticoagulant therapy based on Thrombo test values become rou'ine treatment during hospitalization periods.

By compiling basic data on physical fitness by electrocardiographic exercise itests, a start was made for our rehabilitation programs.

\section{Myocardiopathies}

Due to lack of autopsies, studies in this field have not yet been done.

\section{Cardiac surgery}

Surgery has not remained behind either, closed heart surgery started in 1956. Open Heart Surgery under hypothermia for closing Atrial Septal Defects began in 1961. Cooperation with the Japan Heart Institute (head Prof. S. Sakakibara) enabled us to do open heart surgery using extracorporeal circulation techniques in 1969.

However, due to inadequate financial resources, open heart surgery is carried out occasionally so that our teams do not develop the high tech- 
nical experience and skill which one would hope for.

Open Heart Surgery facilities are nowadays available in Jakarta and Surabaya, East Java.

\section{NOTES:}

The cartoons are made by Dr. Bisono from the Surgical Department University of Indonesia. Orhiba is an abbreviation of "Olah Raga Hidup Baru", literally meaning new life physical exercise.

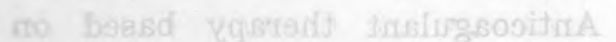

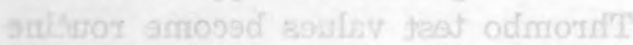

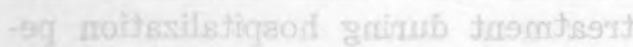

aboir

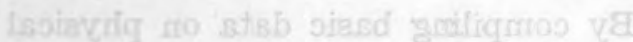

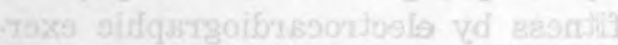

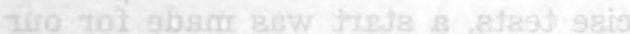

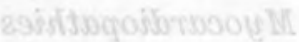

cit goibuta aslaqujus lo zlasi of ond

valob m9od tev tor grad blail airl

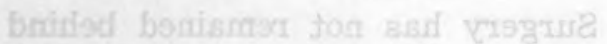

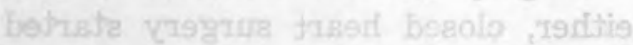

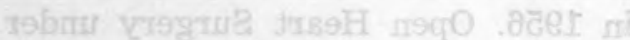

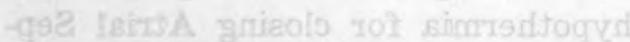

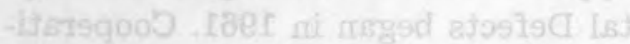

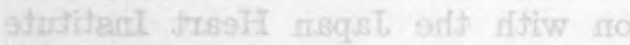

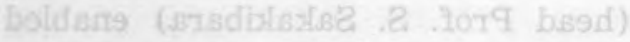

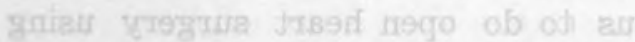

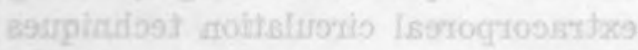
laismanil atsupgbsmi of $9 u b$ isvowoH

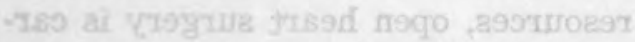
wo tadt os vilsmoiasoso fuo barl -doat sigial snlt goleveb jom ob amsej

\section{Epidemiology}

Due to lack of funds and forces data on Epidemiological studies are not available yet.
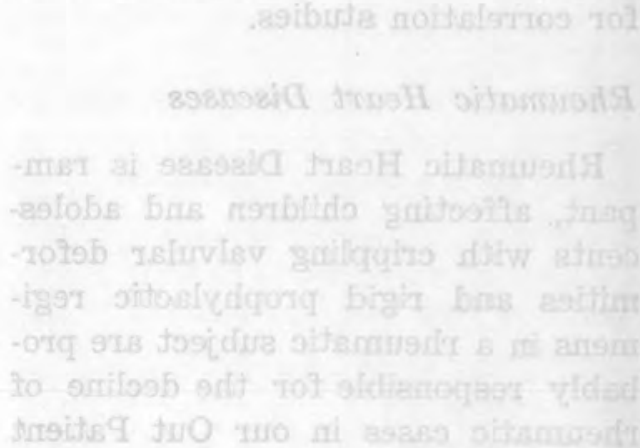

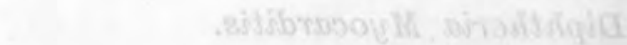

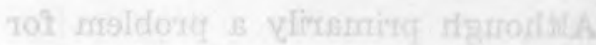

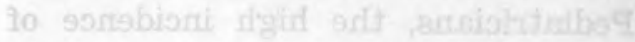

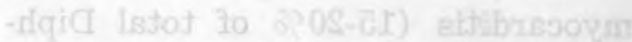

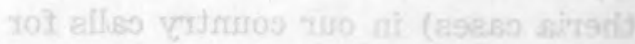
-90 babsarb orlt Hoqcue oigoloibuss

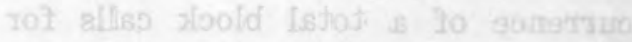

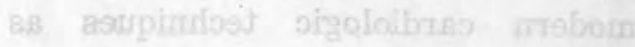

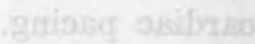

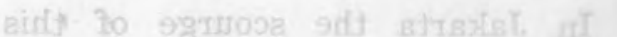

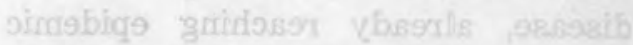
fasintrutos Limfambiti ni Buoitrocong mi entiseb grufbmenc sidsoiton ai -9rgुer arsey 9vitouborg tBom a'nam

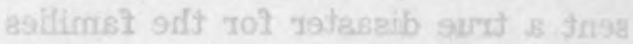
Xateruros bris 